THE WABASH CENTER

JOURNAL on TEACHING

\title{
Success After Tenure: Supporting Mid-Career Faculty
}

\author{
Vicki L. Baker, Laura Gail Lunsford, Gretchen Neisler, Meghan J. Pifer, \\ and Aimee LaPointe Terosky, editors \\ Sterling, VA: Stylus, 2019 (xiii + 365 pages, ISBN 978-1-62036-680-6, \$35.00)
}

\section{Reviewed By \\ Beverley McGuire \\ University of North \\ Carolina Wilmington}

As a mid-career faculty member-which can mean up to seven years after tenure, or more than ten years from retirement after tenure-I was eager to read this book. It shares perspectives of mid-career faculty that resonate with my own experience: increased service and administrative work, a lack of financial resources to support research and writing, rising demands to demonstrate accountability and efficiency, increased pressure to obtain external funding through grant applications, and feeling undervalued and taken for granted by one's institution. The authors also point out that when mid-career faculty assume new positions in academic leadership, it can result in new definitions of what constitutes professional success and also present challenges in how to balance loyalty to one's discipline and to one's institution (123).

Success After Tenure offers ways in which faculty members and institutions can find opportunities despite such manifold challenges, emphasizing the importance of faculty agency (what faculty believe to be possible and what they do to move towards these goals) and strategic response (how faculty can uphold their priorities and passions despite their increased workloads). The authors summarize a history of faculty development in the United States, beginning with the age of the scholar (1950s to 1960s) focused on advancing faculty scholarship, the age of the teacher (mid-1960s to 1970s) emphasizing teaching skills, the age of the developer (1980s) focusing on faculty needs across career stages and faculty learning communities, and the age of the learner (1990s) shifting the focus to student learning (Sorcinelli et al., Creating the Future of Faculty Development, [Anker, 2006]). As many would agree, we are now in the age of evidence with "a focus on assessing the impact of instruction on student learning, of academic programs on student success, and of faculty development within institutional mission priorities" (Beach et al., Faculty Development in the Age of Evidence, [Stylus, 2016], 12). They acknowledge that the social environment plays a significant role in a mid-career faculty member's ability to make changes and commit to new practices (117), emphasizing that fit and feelings of belonging factor into a faculty member's career growth, professional development, productivity, and sense of satisfaction (168).

The authors suggest several ways for improving faculty vitality, including balance, challenge seeking, creativity, curiosity, motivation, optimism, and risk-taking (167). Many authors suggest that scholarship of teaching and learning (SoTL) provides a means for mid-career faculty to build on or re-identify their scholarly paths (100). They draw from Ernest Boyer's expanded vision of scholarship that includes discovery, integration, application, and teaching: "a recognition that knowledge is acquired through research, through synthesis, through practice, and through teaching" (Boyer, Scholarship Reconsidered, [Jossey-Bass, 2016], 86).

Hillary Steiner suggests that synergistic citizens-those whose capacity for self-reflection, interest, and agency prompts them to seek out opportunities for being creative, productive, and relevant in their teaching-would particularly benefit from teaching in first-year student learning communities, which allow faculty "to reimagine their pedagogical approaches through an interdisciplinary, scholarly lens" (142).

The authors underscore the vital role of faculty writing groups, support for sabbaticals, leadership institutes and faculty development workshops, and they emphasize the power of mentoring and peer networking for mid-career faculty. Regular check-ins can be an important source of accountability, allow one to vent frustration or share progress, and enable small group or individual coaching. Mentors can help mentees reflect on their career decisions, review obstacles, and workshop ideas of how to overcome barriers (186). 
The book acknowledges that women faculty and faculty of color are disproportionately burdened by service demands (205), that gender adversely affects career progression, with women spending longer at the associate professor rank and being less likely to advance to full professor (225), and that implicit bias and other barriers contribute to a lack of women's visibility, mobility, and leadership in academic institutions (161-162). To develop mid-career women's sense of agency around their career advancement, they emphasize the importance of workshops, mentoring, and networking programs (228). The chapter titled “Navigating a Foggy Climate: Women Associate Professors' Sense of Agency and Work Environment Experiences" identifies five areas where women face greater challenges than men at the same rank: workload, work-life balance, resources, networks, and agency in career advancement (285). The authors present a set of recommendations that are useful for departments and programs interested in reducing ambiguity in service expectations, creating more equitable workload distributions, reducing ambiguity in available resources and professional networks, and demystifying standards for promotion (303-305).

This book will interest not only mid-career faculty members like myself, but those responsible for faculty development at their colleges, universities, and theological schools. The chapters cover a broad range of institutional contexts and present evidence from substantial bodies of research. 